\title{
Assessment of the accuracy of an ultrasound elastography liver scanning system using a PVA-cryogel phantom with optimal acoustic and mechanical properties
}

\author{
S Cournane $^{1}$, L Cannon ${ }^{2}$, J E Browne ${ }^{2}$ and A J Fagan ${ }^{1,3}$ \\ ${ }^{1}$ Dept. Medical Physics \& Bioengineering, St. James's Hospital, Dublin 8, Ireland \\ ${ }^{2}$ Medical Ultrasound Physics and Technology Group, School of Physics, Dublin Institute of Technology, \\ Kevin's Street, Dublin 8, Ireland. ${ }^{2}$ \\ ${ }^{3}$ Centre for Advanced Medical Imaging (CAMI), St. James's Hospital, Dublin 8, Ireland.
}

\begin{abstract}
The accuracy of a transient elastography liver-scanning ultrasound system was assessed using a novel application of PVA-cryogel as a tissue-mimicking material with acoustic and shear elasticity properties optimized to best represent those of liver tissue. Although the liver-scanning system has been shown to offer a safer alternative for diagnosing liver cirrhosis through stiffness measurement, as compared to the liver needle biopsy exam, the scanner's accuracy has not been fully established. The Young's elastic modulus values of 5-6wt\% PVA-cryogel phantoms, also containing glycerol and $0.3 \mu \mathrm{m} \mathrm{Al}_{2} \mathrm{O}_{3}$ and $3 \mu \mathrm{m} \mathrm{Al}_{2} \mathrm{O}_{3}$, were measured using a 'gold standard' mechanical testing technique and transient elastography. The mechanically measured values and acoustic velocities of the phantoms ranged between $1.6-16.1 \mathrm{kPa}$ and $1540-1570 \mathrm{~m} / \mathrm{s}$, respectively, mimicking those observed in liver tissue. The values reported by the transient elastography system overestimated the Young's elastic modulus values representative of the progressive stages of liver fibrosis by up to $32 \%$. These results were attributed to the relative rather than absolute nature of the measurement arising from the singlepoint acoustic velocity calibration of the system, rendering the measurements critically dependent on the speed of sound of the sample under investigation. Given the wide range of acoustic velocities which exist in the liver, spanning healthy tissue to cirrhotic pathology, coupled with the system's assumption that the liver is approximately elastic when it is rather highly viscoelastic, care should be exercised when interpreting the results from this system in patient groups.
\end{abstract}




\section{Introduction}

It has been found that the mechanical properties of tissue correlate with its pathological condition and hence the study of properties such as the Young's modulus can provide a method for differentiating between different pathological states in tissue (Yeh et al., 2002; Sandrin et al., 2002; Brusseau et al., 2001). While palpation remains the most commonly used technique in a clinical setting for assessing tissue stiffness, whereby regions of increased stiffness serve as an indicator of diseased tissue, the need for a more sensitive, more penetrating, non-invasive and quantitative means of measuring tissue stiffness has drawn significant attention to the rapidly developing area of elastography (Park and Maniatty, 2006; Sandrin et al., 2003; Yamakoshi et al., 1990). Techniques in magnetic resonance elastography (MRE) and ultrasound elastography are beginning to provide more pathologically sensitive and clinically useful information which enhance the interpretation of conventional radiological imaging scans (Asbach et al., 2008; Sandrin et al., 2003). Four main ultrasound elastography approaches have been developed to date: static elastography, dynamic elastography, remote elastography and transient elastography. The first three methods are generally coupled with B-mode techniques, investigating the elastic nature of the compliant tissue and presenting this information in the form of a relative strain map frequently referred to as an "elastogram", superimposed on the B-mode image of the tissue. This approach is very useful as a functional or parametric image of the tissue is overlaid on the anatomical image. Transient elastography, on the other hand, does not provide an anatomical image of elasticity, but rather makes a quantitative stiffness measure of the interrogated tissue (Sandrin et al., 2002; Gao et al., 1996; Céspedes et al., 1993). The principal application of transient elastography has been in liver function assessment, where an increase in liver stiffness can indicate the progression of different pathologies such as chronic liver disease, alcoholic liver disease and non-alcoholic fatty liver disease to name but a few.

Chronic liver disease is extremely common worldwide, with estimated figures of 350 and 180 million people chronically infected with the hepatitis $\mathrm{B}$ and hepatitis $\mathrm{C}$ viruses, respectively (WHO, 2000). These conditions, together with alcoholic liver disease and non-alcoholic fatty liver disease, among others, may lead to the development of extensive fibrosis or cirrhosis of the liver, with the latter associated with an increased risk of morbidity and mortality (Rojkind, 2001; Nahon et al., 2008; Yoneda et al., 2008; Zhou and Lu, 2009). The Fibroscan ${ }^{\circledR}$ system (Echosens, France) utilizes transient elastography to determine the mechanical status of the liver through the application of 1-D reflective mode transient elastography and has emerged as a means of estimating the extent of fibrosis in the liver in a clinical setting via a direct measurement of the liver stiffness. The system produces a low-frequency shear wave for propagation in the liver tissue, the stiffness of the which can then be estimated by measuring the 
velocity of the shear wave using a pulse-echo mode ultrasound (in $\mathrm{MHz}$ frequency range) and cross correlation (Sandrin et al., 2002).

Currently, large needle biopsy (LNB) followed by histopathological analysis is regarded as the gold standard method for assessing the health of the liver (Zhou and Lu, 2009); however, examination by LNB may introduce morbidity $(0.1 \%)$ and mortality $(0.01 \%)$ risks due to its invasive nature (McGill et al., 1990). Furthermore, potential errors may be introduced due to intra-observer variations (Regev et al., 2002; Rousselet et al., 2005), and the limited volume of liver tissue actually sampled by LNB, which typically represents an order of $0.002 \%$ of the mass of the liver (Bedossa et al., 2003). The Fibroscan ${ }^{\circledR}$ system provides an instantaneous, noninvasive stiffness measure of an interrogated area of the liver, thereby, reducing the sampling error and inherent risks. The METAVIR (Bedossa and Poynard, 1996) classification procedure used for LNB categorizes the development of hepatic fibrosis according to 5 progressive stages ranging from F0, regarded as a healthy liver state, to $\mathrm{F} 4$, the most severe stage of fibrosis. Several studies comparing data from LNB and the Fibroscan ${ }^{\circledR}$ system have shown good correlation between the METAVIR classification and stiffness values reported by the scanner, and consequently the Fibroscan ${ }^{\circledR}$ system is emerging as a credible alternative to LNB and histopathology for safer and more rapid diagnosis of cirrhosis (Nguyen-Khac and Capron, 2006; Sandrin et al., 2003; de Lédinghen and Vergniol, 2008; Verveer and de Knegt, 2006). However, such empirical correlations between the degree of liver fibrosis and Fibroscan ${ }^{\circledR}$ measurements may not hold for different liver conditions, such as Hepatitis $\mathrm{C}$ and non-alcoholic fatty liver disease (Yoneda et al., 2008; Ziol et al., 2005). To replace LNB as the sole diagnostic technique for a variety for liver diseases, it is clear that the absolute accuracy of an elastography ultrasound system must be determined, so that clinicians can have confidence that the measured values accurately reflect the underlying pathology. To date, no such accuracy determination has been performed for the Fibroscan ${ }^{\circledR}$ system, in large part due to a lack of a suitable test phantom containing tissue-mimicking materials (TMM) with appropriate acoustical and mechanical properties to simulate both healthy and diseased liver tissue.

Tissue mimicking materials currently being researched for use as elastography phantoms include: oil-in-agar, oil-in-gelatin and agar dispersions (Madsen et al., 2005); co-polymer in oil (Oudry et al., 2009); polyacrylamide gels (Klinkosz et al., 2008; Luo and Konofagou, 2009); and a relatively novel approach using poly(vinyl alcohol) cryogel (Brusseau et al., 2001; Fromageau et al., 2007; Chu and Rutt, 1997; Surry et al., 2004). Oil-in-agar, oil-in-gelatin and agar dispersions can achieve Young's modulus values ranging from $5-135 \mathrm{kPa}$, which is representative of soft tissue (de Korte et al., 1997; Madsen et al., 2005, 2006). Copolymer-in-oil TMM phantoms can achieve optimal mechanical properties (Oudry et al., 2009); however, the 
range of acoustic velocities achievable with this material $(1420-1464 \mathrm{~m} / \mathrm{s})$ is much lower than that of soft tissue (Szabo, 2004). Polyarcylamide gel requires special precautions during preparation due to its toxicity (Culjat et al., 2010), and in addition the material has been reported as fragile (Oudry et al., 2009).

The stiffness properties of poly(vinyl alcohol) cryogel (PVA-C) can be manipulated by processing the material through a number of freeze/thaw cycles, varying the PVA concentration and also by controlling the rate of thawing (Chu and Rutt, 1997; Brusseau et al., 2001; Surry et al., 2004; Pazos et al., 2009). The versatility of PVA-C as a TMM phantom across ultrasound and MR modalities has been well documented (Surry et al., 2004), while its robustness and strength has been identified in work where the material has been successfully used as an aortic vessel phantom (Chu and Rutt, 1997). Studies on the optimisation of interrogative methods for identifying pressure ulcers in their early stages have successfully utilized PVA-C to mimic the tissue affected by the pressure ulcers (Deprez et al., 2007), while anthropomorphic brain phantoms, multi-volume stenosed vessel phantoms and breast biopsy phantoms have also been successfully developed using polyvinyl alcohol cryogel for multi-modality studies (Surry et al., 2004). Acoustic velocity values measured in $10 \%$ by weight PVA concentration processed through 1 to 10 freeze thaw cycles were found to vary between 1525 and $1560 \mathrm{~m} / \mathrm{s}$ (Fromageau et al., 2007), which is similar to acoustic velocities found in soft tissue (Szabo, 2004). However, the reported Young's elastic modulus values produced in PVA-C phantoms to date have been limited to between 20 and $600 \mathrm{kPa}$ (Fromageau et al., 2003), and this material has not been used to mimic the lower elastic modulus ranges of the liver. It should be noted that PVA-C is nearly lossless and therefore does not mimic the lossy properties of the liver.

The aim of the current work was to investigate the use of PVA-C as a TMM for liver elastography by manipulating its mechanical and acoustic properties to achieve liver stiffness values spanning the range from healthy liver tissue to severe fibrosis, and to develop a range of test phantoms based on this TMM to quantify the accuracy of the Fibroscan ${ }^{\circledR}$ system's measurements.

\section{Materials and Methods}

\subsection{PVA-C phantom preparation}

$99+\%$ hydrolysed poly(vinyl alcohol) powder (Sigma-Aldrich ${ }^{\circledR}$ typical $M_{w} 89,000-98,000$ ) was chosen to make the PVA liquids due to its high level hydrolysis. A rigorous process for the preparation of liquid PVA mixture was adhered to throughout the study, with 5 - $6 \mathrm{wt} \%$ PVA solution typically used, a concentration that was empirically determined to achieve low stiffness material. The mixture was made up of $0.05 \%$ by weight concentration benzalkonium chloride to 
inhibit any bacterial or microbiological activity in the gels and resultant cryogels. Aluminium oxide $\left(\mathrm{Al}_{2} \mathrm{O}_{3}\right)$ acoustic scatterers of an average particle size of $0.3 \mu \mathrm{m}$ (Logitech ultrafine Aluminium Oxide powder, LOT O81236) were also included in the mixture to affect the acoustic attenuation coefficient. 0 - $16 \%$ by weight glycerol $\left(\mathrm{C}_{3} \mathrm{H}_{8} \mathrm{O}_{3}\right)$ concentration, in the form of $\geq 99.0 \%$ Glycerol ReagentPlus ${ }^{\circledR}$ (Sigma-Aldrich ${ }^{\circledR}$ ), was also used in the mixture to vary the acoustic velocity of the cryogel samples.

The PVA powder along with other ingredients, were mixed with de-ionised water and heated to $90{ }^{\circ} \mathrm{C}$ in a water bath in order to achieve complete dissolution to a liquid gel, with the mixture covered to minimize dehydration. The mixture was then stirred for 1 hour at $100 \mathrm{rpm}$ to break any aggregates of powder, reduce particulate coagulation and ensure a homogenous solution. Once the mixture of PVA, scatterers, anti-bacterial agent and acoustic velocity modifier had been homogenously mixed, it was weighed with any loss in mass replaced with de-ionised water. The mixtures were poured into airtight moulds, thereby creating a humid environment to ensure no skin formed on the surface of the solution as it cooled to room temperature. The mixture was then poured into cylindrical moulds and left to rest for an additional 1 - 2 hours to allow air bubbles rise to the surface for removal.

Solidification and polymerisation of the samples was induced by freeze-thaw cycling ( $1-6$ cycles) in a temperature-controlled environment. The freeze-thaw cycle lasted 24 hours with an initial 12 hour stage during which the sealed samples were subjected to a temperature of $-30{ }^{\circ} \mathrm{C}$ in a conventional chest freezer. The subsequent 12 hour thaw phase followed by introducing the samples to an environment of $15{ }^{\circ} \mathrm{C}$. Once the freeze-thaw process had been completed with physical cross-linking achieved, a glycerol solution corresponding to that of the PVA-C was added and the samples were submerged in individual sealed containers. Storage of PVA-C using de-ionised water has been reported to prevent any dehydration of the cryogel polymer (Surry et al., 2004). In this study, a glycerol solution containing the same glycerol concentration as that used in the phantoms was added to prevent any glycerol leaching from, or dehydration of, the PVA-C, a method that has been shown to keep PVA-C stable for up to 2 years (King, 2009). In cases where investigations of the physical and acoustic characteristics of the phantoms were carried out, the samples were sectioned using a surgical-grade scalpel. It was necessary to allow the samples to condition for 3 hours prior to sectioning, a process that allows the phantoms to reach thermal equilibrium with the ambient temperature (ISO-7743, 2008).

A number of different experiments, varying the various ingredients of the phantoms, were carried out to study the resultant effects on the tissue-mimicking material. To investigate the effect of different phantom volumes on boundary effects and on the homogeneity of the 
phantoms' mechanical properties, cylindrical PVA-C phantoms of diameters 6.7, 9.2, 11, $13 \mathrm{~cm}$ and height $10 \mathrm{~cm}$ were produced, sectioned, and their sections mechanically tested to determine their Young's elastic modulus values and homogeneity. To optimize the acoustic attenuating properties of the PVA-cryogel material, to produce a reasonable ultrasonic signal and investigate the uniformity of the attenuation coefficient, experiments were carried out on three different phantoms by the inclusion of $0.3 \mu \mathrm{m} \mathrm{Al}_{2} \mathrm{O}_{3}$ and $3 \mu \mathrm{m} \mathrm{Al}_{2} \mathrm{O}_{3}$ acoustic scatterers. Phantom A contained no scatterers, while phantoms B and C contained $(0.88 \mathrm{wt} \%$ of $0.3 \mu \mathrm{m}$ $\mathrm{Al}_{2} \mathrm{O}_{3}$ and $0.94 \mathrm{wt} \% 3 \mu \mathrm{m} \mathrm{Al} \mathrm{O}_{3}$ ), and ( $2 \mathrm{wt} \%$ of $0.3 \mu \mathrm{m} \mathrm{Al}_{2} \mathrm{O}_{3}$ ), respectively These phantoms were also sectioned and their acoustic properties investigated. The water/glycerol proportion of the tissue-mimicking material determines the speed of sound and fluid density (Ramnarine et al., 1998), and thus, the effects of the addition of $0-20 \mathrm{wt} \%$ glycerol, with an acoustic velocity of $1904 \mathrm{~m} / \mathrm{s}$ (Onda, 2006), on the acoustic velocity of PVA-C was investigated through experimental phantoms of diameter $6.7 \mathrm{~cm}$ and thickness $2.5 \mathrm{~cm}$, and processed through 3 freeze/thaw cycles. A final experiment, for the assessment of the accuracy of the Fibroscan ${ }^{\circledR}$ system was carried out where a series of 8 PVA-C phantoms, of $13 \%$ by weight glycerol, $2 \%$ by weight $0.3 \mu \mathrm{m} \mathrm{Al} \mathrm{O}_{3}$ scatterers and the anti-bacterial agent were produced.

\subsection{Measurement of the acoustic properties of the TMM}

The acoustic velocity and attenuation coefficient of the TMM samples were determined using an in-house built scanning acoustic macroscope (SAM) system. The SAM system utilizes the pulse-echo substitution method to determine the acoustic and attenuation properties of its transmission medium (Browne et al., 2003; Schwan and Carstensen, 1952). The apparatus consisted of a pulse receiver (Model 5052PR, Panametrics, UK), immersion broadband transducer (5.15 - 9.44 MHz, Panametric, UK), high-speed digitiser (250 MS/s, bandwidth of $125 \mathrm{MHz}$ with 2 simultaneously sampled channels, National Instruments, USA), water tank and transducer holder. The transducer acted as both the transmitter and receiver with the transmitted ultrasonic pulses reflected by the glass bottom and received by the same transducer. Once received, the RF signal was amplified and outputted to the digitiser where it was saved for subsequent analysis. Two scans were acquired with the transducer submerged in a tank of degassed water positioned such that the steel plate reflector was at its focus. The first scan, which serves as a reference scan, was captured with no tissue mimicking material (TMM) sample present in the water, while during the second scan capture (the sample scan), a TMM phantom was positioned in the path of the ultrasonic beam. Each measurement took less than one minute, and hence any leaching of glycerol from the samples into the degassed water of the SAM system was assumed to be negligible. The sample temperature was maintained at $20 \pm$ $0.5^{\circ} \mathrm{C}$ in all cases. In this study, the 7.5 MHz SAM broadband transducer, of range $5.15-9.44$ 
$\mathrm{MHz}$, was employed since it is the closest in frequency to the Fibroscan ${ }^{\circledR}$ system's probe frequency of $3.5 \mathrm{MHz}$.

Signal processing for determining the speed of sound and attenuation measurements was performed in MATLAB ${ }^{\mathrm{TM}}$ (MathWorks Inc., Natick, MA). The fast Fourier transform (FFT) of each of the signals was obtained with the acoustic velocity $(c)$ and attenuation coefficient $(\alpha)$ of each of the TMM samples determined by comparing the resultant frequency spectra following measurements by the transducer with and without the sample in place. The speed of sound of the samples was determined using the equation:

$\frac{1}{c_{s}}=\frac{1}{c_{w}}-\frac{\Delta t}{2 d}$

where $c_{s}$ is the speed of sound in the phantom sample, $c_{w}$ is the speed of sound in the degassed water, $d$ is the thickness of the phantom sample and $\Delta t$ is the resultant time shift in the RF pulse with and without the phantom sample in the path of the ultrasonic beam. The attenuation as a function of frequency, $f$, was calculated from the $\log$ difference between the two spectra (Browne et al., 2003; Schwan and Carstensen, 1952), given as:

$\alpha(f)=-\frac{20}{2 d} \log _{10} \frac{A(f)}{A_{0}(f)}$

where $A_{0}$ is the magnitude of the signal with no sample in place and $A$ is the magnitude with the sample in the path of the beam.

\subsection{Measurement of the mechanical properties of the TMM}

PVA-cryogel phantoms were mechanically compression tested using a computer-controlled Lloyd Instruments LR30KPlus system (Ametek ${ }^{\circledR}$ measurement and calibration technology, USA). Two interchangeable load cells (500 N and $3 \mathrm{kN}$ ) were used in the compression testing process. Samples were tested according to a standard compression protocol (ISO-7743, 2008). The metal plates, through which the compressive force was applied, were considered to be lubricated since a fine film of water was present on both faces of the samples. Thus with lubricated test pieces, the results are dependent only on the modulus of the material and are independent of the test piece shape, provided that complete slip conditions are achieved. The standard defines the compression stress as that stress applied which causes a deformation of the test piece in the direction of the applied stress, expressed as the force divided by the original area of cross-section perpendicular to the direction of application of the force. The compression 
strain is defined as the deformation of the test piece in the direction of the applied stress divided by the original dimension in that direction, commonly expressed as a percentage of the original dimension of the test piece. The compression modulus, also known as the secant modulus, is the applied stress calculated on the original area of cross-section divided by the resultant strain in the direction of application of the stress. The standard specifies a certain set of sample dimensions that should be adhered to; however, an extrapolation of results for non-standard samples under lubricated conditions is also detailed. This is especially useful for this work as it provides a means of determining the mechanical properties of samples with a variety of dimensions and accounts for the change in sample cross-sectional area during compression.

Sample preparation involved conditioning the test pieces at the mechanical testing temperature $\left(20 \pm 0.5^{\circ} \mathrm{C}\right)$ for 3 hours before testing, while a 3 hour conditioning period is also recommended prior to any sectioning or cutting of samples (ISO-7743, 2008). Test samples were inserted centrally into the compression plate assembly with the upper compression plate lowered manually until a positive load of approximately $0.5 \mathrm{~N}$ was applied. The machine operated at a speed of $50 \mathrm{~mm} / \mathrm{min}$ until a strain of $30 \%$ was reached, with the strain then automatically released at the same rate of $50 \mathrm{~mm} / \mathrm{min}$, completing one compression and release cycle. Four more cycles were carried out forming an uninterrupted sequence of compression and release cycling. In accordance with the international standard (ISO-7743, 2008), calculations of the mechanical properties of the phantom material were performed with data from the release stage of the $5^{\text {th }}$ compression and release cycle. The samples used were considered to be nonstandard as defined by Annex A of ISO 7743:2008, which for small strains, up to about $5 \%$, gives the approximation:

$\sigma=E \varepsilon$

where $\sigma$ is the average strain and $E$ is the Young's modulus. Accordingly, this method was used for determining the stiffness of the constructed samples and phantoms.

\subsection{Assessment of the Fibroscan ${ }^{\circledR}$ system accuracy}

The Fibroscan ${ }^{\circledR}$ system (Echosens, Paris) is composed of a probe, as shown in Figure 1, a dedicated electronic system and a control unit. The shear elasticity probe consists of a low-frequency piston-like vibrator with an ultrasonic single-element transducer operating at 3.5 MHz built on the tip of the vibrator operated in transmit / receive mode (Sandrin et al., 2003). The Fibroscan ${ }^{\circledR}$ system works on the premise that the low frequency $50 \mathrm{~Hz}$ excitation in the medium of interest causes the propagation of a shear wave (1 to $10 \mathrm{~m} / \mathrm{s})$, the velocity of which can be measured using the $3.5 \mathrm{MHz}$ ultrasonic wave $(\sim 1500 \mathrm{~m} / \mathrm{s})$. The shear wave is 
generated by the piston-like vibrator, which gives a 'flick' to the surface of the interrogated medium. The shear wave propagation is tracked using a cross-correlation technique and then displayed in the form of an elastogram, as illustrated in figure 2, which shows the amplitude of the strain induced as a function of depth and time in the interrogated region. The elasticity of the region of interest (ROI) can be derived from the elastogram by calculating the velocity of the low frequency elastic wave located from 25 to $65 \mathrm{~mm}$ below the skin surface. This ROI has been set by the manufacturers to avoid the subcutaneous tissue and the liver fibrous capsule of the patient, and to ensure that the signal to noise ratio (SNR) of the ultrasound allows a good estimation of the tissue deformations.

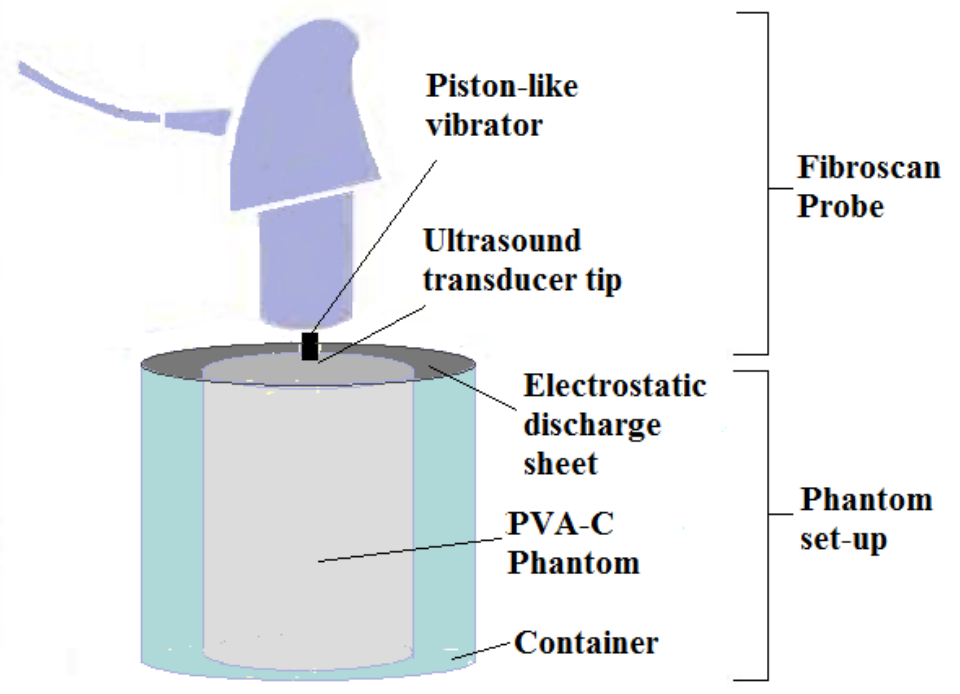

Figure 1. Schematic of the Fibroscan ${ }^{\circledR}$ system and Phantom set-up.

The low-frequency elastic wave propagates mainly as a shear wave, presenting as a longitudinal component in the medium of propagation. The shear velocity is of the order of $1 \mathrm{~m} / \mathrm{s}$, whereas compression ultrasonic waves travel at a greater rate of approximately $1500 \mathrm{~m} / \mathrm{s}$. For the purpose of elasticity estimation, the Fibroscan ${ }^{\circledR}$ system assumes the liver to be a non-viscous, isotropic and soft elastic medium (Sandrin et al., 2002). In the case of soft media and where viscosity is ignored, $\lambda \gg \mu$, the Young's modulus $E$ and the Poisson ratio $\sigma$ reduce to:

$$
\begin{aligned}
& E=3 \mu \\
& \sigma=\frac{1}{2}
\end{aligned}
$$

On the basis of this assumption, the Young's modulus only depends on the shear modulus which, if dissipation is ignored, is directly dependant on the shear velocity given as:

$$
E=3 \rho V_{S}^{2}
$$


As a result, the Young's modulus of a soft non-dissipative medium can be deduced (Royer and Dieulesaint, 2000) and the Fibroscan ${ }^{\circledR}$ system thus reports an estimated stiffness value for the interrogated region of the liver tissue. The fact that the liver is not elastic, but rather viscoelastic (Asbach et al., 2008) will be discussed later.

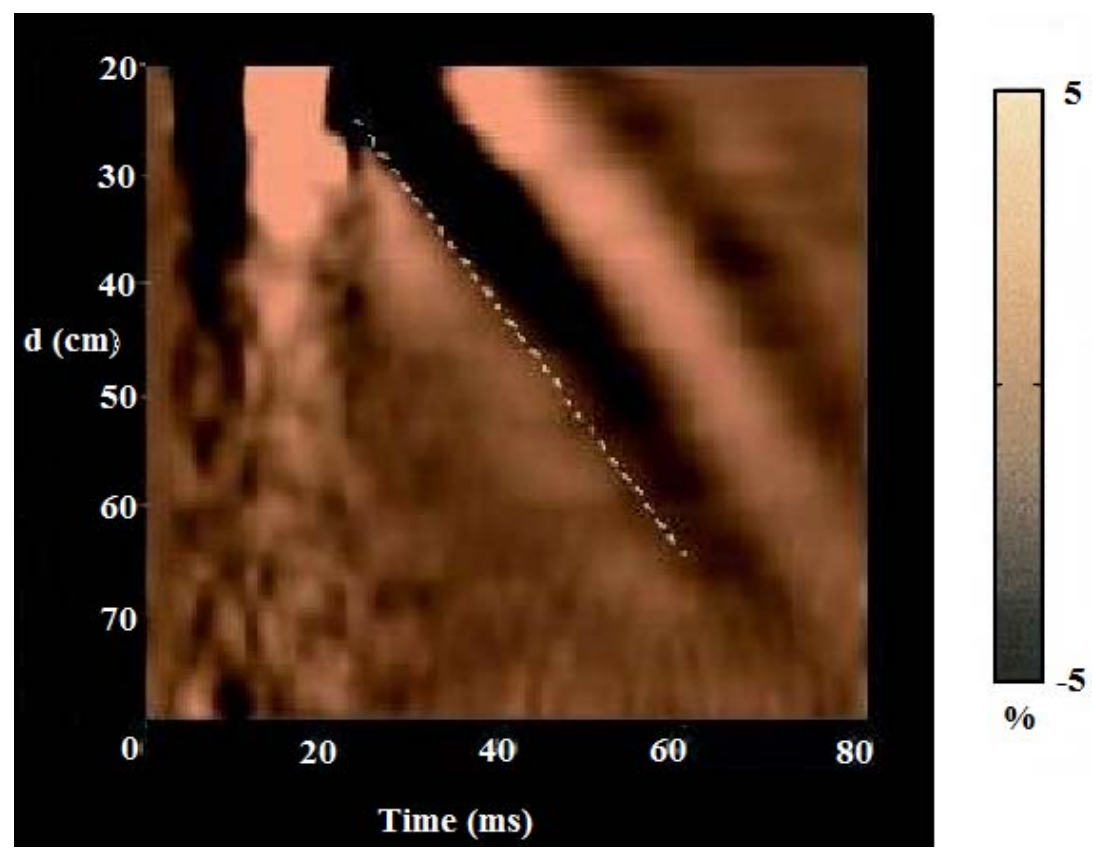

Figure 2. Example of an elastogram measured by the Fibroscan ${ }^{\circledR}$ system, displaying the amplitude of the strains induced in a healthy patient liver as a function of depth $(d)$ and time. The stiffness measurement is derived from the velocity of the shear wave propagated in the liver tissue.

When scanning the constructed cryogel phantoms with the Fibroscan ${ }^{\circledR}$ system (as shown in Figure 1), the phantoms were typically centred in a $92 \mathrm{~mm}$ diameter container ensuring no contact was made with the rigid container walls, thereby decreasing the potential for reflected shear waves which would compromise the measurement accuracy. The Fibroscan ${ }^{\circledR}$ system only makes a measurement when the probe is applied to the sample with a minimum pressure, and consequently to avoid damaging the surface of the sample and reducing anisotropic effects, a taut electrostatic discharge (ESD) sheet was overlaid on the top surface of the test phantoms. Thus, when the tip of the probe was pressed into the centre surface of the phantom, the ESD bore most of the pressure applied, while still allowing for contact between the probe and phantom surface and propagation of the shear wave into the sample. A thin film of water was present at the top surface of the phantom to ensure adequate coupling allowing for a good ultrasonic signal. A pressure gauge on the Fibroscan ${ }^{\circledR}$ system offers a guide to the user detailing when enough pressure has been exerted by the probe tip. 10 measurements were performed for 
each of the 8 phantoms at a sample temperature of $20 \pm 0.5^{\circ} \mathrm{C}$, with the median value and interquartile range (IQR) of each recorded by the scanner.

\section{Results and Discussion}

\subsection{Investigation of low concentration PVA cryogels}

Preliminary experiments were conducted to establish whether PVA-C possesses the necessary Young's elastic modulus values to mimic those reported for human liver tissue. Table 1 lists the compression tested Young's modulus values of $6 \mathrm{wt} \%$ PVA-C samples as a function of the number of freeze-thaw cycles through which each was processed. The samples, of diameter 67 $\mathrm{mm}$ and thickness $25 \mathrm{~mm}$, proved to be Hookean in regions of lower strain ( $0-15 \%)$, where a linear relationship between stress and strain was observed. This characteristic is observed in elastic material (Fung, 1993) and also in viscoelastic material such as human liver and soft tissue (Yeh et al., 2002; Nava et al., 2008). The data from this region was used to deduce the Young's modulus of the sample through weighted linear least squares regression.

Table 1. Mechanically tested Young's elastic modulus values of $6 \mathrm{wt} \%$ PVA-C samples, along with the corresponding standard errors, as a function of the number of freeze-thaw cycles.

\begin{tabular}{lcccc}
\hline $\begin{array}{l}\text { No. of freeze/thaw } \\
\text { cycles }\end{array}$ & 1 & 2 & 3 & 4 \\
\hline $\begin{array}{l}\text { Young's elastic } \\
\text { Modulus (kPa) }\end{array}$ & $2.5 \pm 0.09$ & $2.7 \pm 0.09$ & $3.5 \pm 0.1$ & $5.4 \pm 0.12$ \\
\hline
\end{tabular}

The results show the achieved stiffness values to vary between $2.5-5.4 \mathrm{kPa}$, with an increase in the Young's elastic modulus values produced with increasing freeze/thaw cycles. This pattern is consistent with other PVA-cryogel studies which have also demonstrated the material to be approximately incompressible, justifying the assumption that the shear velocity of the material is directly related to the Young's modulus (Fromageau et al., 2007). Higher strains of up to $50 \%$ were applied to the cryogel and did not result in any rupturing or breakage of the material, thus demonstrating the robustness of the cryogel. The Young's modulus of healthy human liver tissue, as measured by the Fibroscan ${ }^{\circledR}$ system and corresponding to a METAVIR biopsy score of F0 - F1, have been reported to be in the range 3.35 - $5.1 \mathrm{kPa}$ (Sandrin et al., 2003). Previous cryogel phantom studies have employed $10 \%$ by weight PVA and have yielded Young's modulus values of the order of $20 \mathrm{kPa}$ (Fromageau et al., 2007). It is clear from the current study that PVA-C possesses the necessary mechanical properties for inclusion into test phantoms suitable for assessing the Fibroscan ${ }^{\circledR}$ system, and furthermore can be used to produce TMMs of sufficiently low stiffness values to mimic those of healthy liver tissue (i.e. $<5 \mathrm{kPa}$ ), 
as measured by the scanner. At a dominant shear wave frequency of $50 \mathrm{~Hz}$, that at which the Fibroscan ${ }^{\circledR}$ system operates, the liver has been shown to be a highly viscous medium (Asbach et al., 2008), and thus while PVA-C can successfully mimic a range of shear elastic modulus values similar to that of the liver, the cryogel is considered to be approximately elastic and therefore does not mimic the shear loss modulus of real liver tissue. For the purpose of this study, however, given the assumption by the Fibroscan ${ }^{\circledR}$ system that the liver is approximately elastic, the properties of PVA-C were considered suitable for assessing the accuracy of the Fibroscan ${ }^{\circledR}$ system.

\subsection{Phantom volume investigation}

The region of interest interrogated by the Fibroscan ${ }^{\circledR}$ system is reported to approximate a cylinder $10 \mathrm{~mm}$ wide and $40 \mathrm{~mm}$ long at depths between $25 \mathrm{~mm}$ to $65 \mathrm{~mm}$ below the skin surface (Sandrin et al., 2003), and thus, it is necessary to employ a phantom of at least $65 \mathrm{~mm}$ in depth. In addition, the mechanically induced transient vibration utilized in transient elastography exhibits reduced sensitivity to boundary effects, as compared with other elastographic techniques, since the transmitted elastic wave can be temporally separated from reflected elastic waves (Sandrin et al., 2003). If it is assumed that a propagated transient wave is reflected by a boundary, the volume of the cryogel phantom should be sufficient such that the path travelled by the reflected wave is long enough to minimize any interference during the acquisition procedure. Accordingly, PVA-C cylindrical phantoms of increasing diameter were produced to investigate the homogeneity of the mechanical properties throughout their respective sections. The Young's Modulus values measured for the cylindrical phantoms of varying sizes revealed an increasing inhomogeneity as the diameter increased, ranging from $12.5 \pm 0.7,10.3 \pm 2.1$, and $9.9 \pm 3.1$ for the $6.7,9.2$ and $11 \mathrm{~cm}$ diameter phantoms respectively, while the $13 \mathrm{~cm}$ diameter phantom did not achieve complete gelation. Although there was also a decrease in the Young's modulus of the phantoms with increasing diameter, the measured stiffness values were within experimental error.

The freezing/thawing rate through which the PVA-C was processed is a critical parameter controlling the polymerisation of the cryogel, allowing for control of the stiffness of the material for a given concentration of PVA (Fromageau et al., 2003; Pazos et al., 2009). During the freeze/thaw cycle, cross-linking occurs when crystal nuclei are generated in the freezing stage, and, on thawing, these nuclei grow into crystallites that act as cross-linking sites for the polymer (Chu and Rutt, 1997). Studies investigating 10\% PVA solutions with variable freeze/thaw cycles have revealed very different mean Young's modulus values in their PVA-C material, resulting from their use of different minimum temperatures for the freezing stage which invariably results in different rates of freezing and thawing. When a temperature of $-40^{\circ} \mathrm{C}$ was 
used, Young's modulus values of $90 \pm 6 \mathrm{kPa}$ for five freeze/thaw cycles were obtained, whereas a higher freezing temperature of $-20^{\circ} \mathrm{C}$ produced material stiffness values of $300 \pm 35 \mathrm{kPa}$ for the same number of freeze/thaw cycles (Fromageau et al., 2003; Fromageau et al., 2007; Hassan et al., 2000). A more recent study investigating the freezing rate of PVA found no significant effect on the ultimate stiffness of the material when variable freezing rates were employed (Pazos et al., 2009). The same study observed no significant difference in the materials stiffness when the maximum temperature for the freeze/thaw cycle was $10^{\circ} \mathrm{C}$ or $20^{\circ} \mathrm{C}$, while a decreased thawing rate produces similar results to an increased number of freeze-thaw cycles (Pazos et al., 2009). Thus, increasing the thawing rate is regarded as a method of creating PVA materials with lower Young's moduli, while another alternative employed in the current study involves the use of lower concentrations of PVA solution (Fromageau et al., 2003; Pazos et al., 2009). The decrease in the homogeneity of the Young's modulus with increased phantom diameter in the current study is possibly due to inhomogenous thawing rates throughout the phantoms: in the 9.2 and $11 \mathrm{~cm}$ diameter phantoms, sections located in the centre of the phantoms showed higher relative Young's modulus values compared to those at the top and bottom, which can be ascribed to lower rates of thawing in the centre compared to the edges. The inhomogeneity of the $6.7 \mathrm{~cm}$ diameter phantom, which exhibited a standard deviation of $5.6 \%$ for the Young's modulus values, compares favourably with values in the region of $8 \%$ common in a commercial elasticity phantom (CIRS, 2009), and hence this dimension was used for all subsequent phantom construction.

\subsection{Acoustic characterisation of PVA-C}

Results of the acoustic attenuation uniformity experiments involving the addition of $\mathrm{Al}_{2} \mathrm{O}_{3}$ acoustic scatterers are illustrated in figures 3 and 4, where profiles of the acoustic attenuation coefficients and acoustic velocities in each phantom are plotted as a function of depth. The data plotted at each depth in these figures represent the average of measurements at five different points in each section, with the error bars representing the standard deviation of these points.

While phantom A exhibits a relatively uniform average attenuation coefficient of 0.13 $\mathrm{dB} / \mathrm{cm} / \mathrm{MHz}$ throughout the phantom, a value consistent with that found in other cryogel studies (Surry et al., 2004), the coefficient is very low as compared with the recommended $0.5-0.7 \mathrm{~dB} / \mathrm{cm} / \mathrm{MHz}$ for soft tissue (IEC-1390, 1996). Indeed, the Fibroscan ${ }^{\circledR}$ system failed to measure the elasticity of this phantom while the presence of the suggested IEC proportion of $\mathrm{Al}_{2} \mathrm{O}_{3}, 0.88 \%$ by weight $0.3 \mu \mathrm{m} \mathrm{Al} \mathrm{O}_{3}$ and $0.94 \%$ by weight $3 \mu \mathrm{m}$ of $\mathrm{Al}_{2} \mathrm{O}_{3}$ scatterers (IEC-1390, 1996) in phantoms $B$ led to successful data acquisition. Phantom $C$ was also successfully scanned by the Fibroscan ${ }^{\circledR}$ system and exhibited a relatively uniform attenuation profile with depth $(0.4 \pm 0.02 \mathrm{~dB} / \mathrm{cm} / \mathrm{MHz})$. A high standard deviation was evident in the attenuation 
coefficients for some sections of phantom B, an effect seen to a lesser extent in the sections of phantoms A and C. This may be due to inhomogeneities in the cryogel material, in addition to inhomogeneities in the spread of scatterers, possibly as a consequence of particle clumping. The introduction of the scatterers had the desired effects of raising the overall attenuation coefficient close to that of soft tissue and enabling the phantoms to be scanned by the Fibroscan ${ }^{\circledR}$ system; however, a significant variation in the coefficient was evident with depth in phantoms B where the bottom section was $0.67 \mathrm{~dB} / \mathrm{cm} / \mathrm{MHz}$, considerably higher than the measured values at other sections in the phantom. This attenuation profile was most likely due to sedimentation of the larger diameter $\mathrm{Al}_{2} \mathrm{O}_{3}$ particles in the relatively low viscosity $6 \mathrm{wt} \%$ PVA solution, an effect that was not evident for phantom $\mathrm{C}$ which only contained $0.3 \mu \mathrm{m} \mathrm{Al}_{2} \mathrm{O}_{3}$ particulate to increase the overall scatter. The inclusion of $\mathrm{Al}_{2} \mathrm{O}_{3}$ scatterers proved necessary for data acquisition by the Fibroscan ${ }^{\circledR}$ system due to the need for higher backscatter to ensure an accurate crosscorrelation process. While a higher attenuation coefficient than that provided by the PVAcryogel alone was required, the absolute value of the attenuation coefficient seemed irrelevant provided sufficient signal was received by the Fibroscan ${ }^{\circledR}$ system. Subsequently, phantoms including $0.3 \mu \mathrm{m} \mathrm{Al}_{2} \mathrm{O}_{3}$ scatterers were only considered for investigations hereafter.

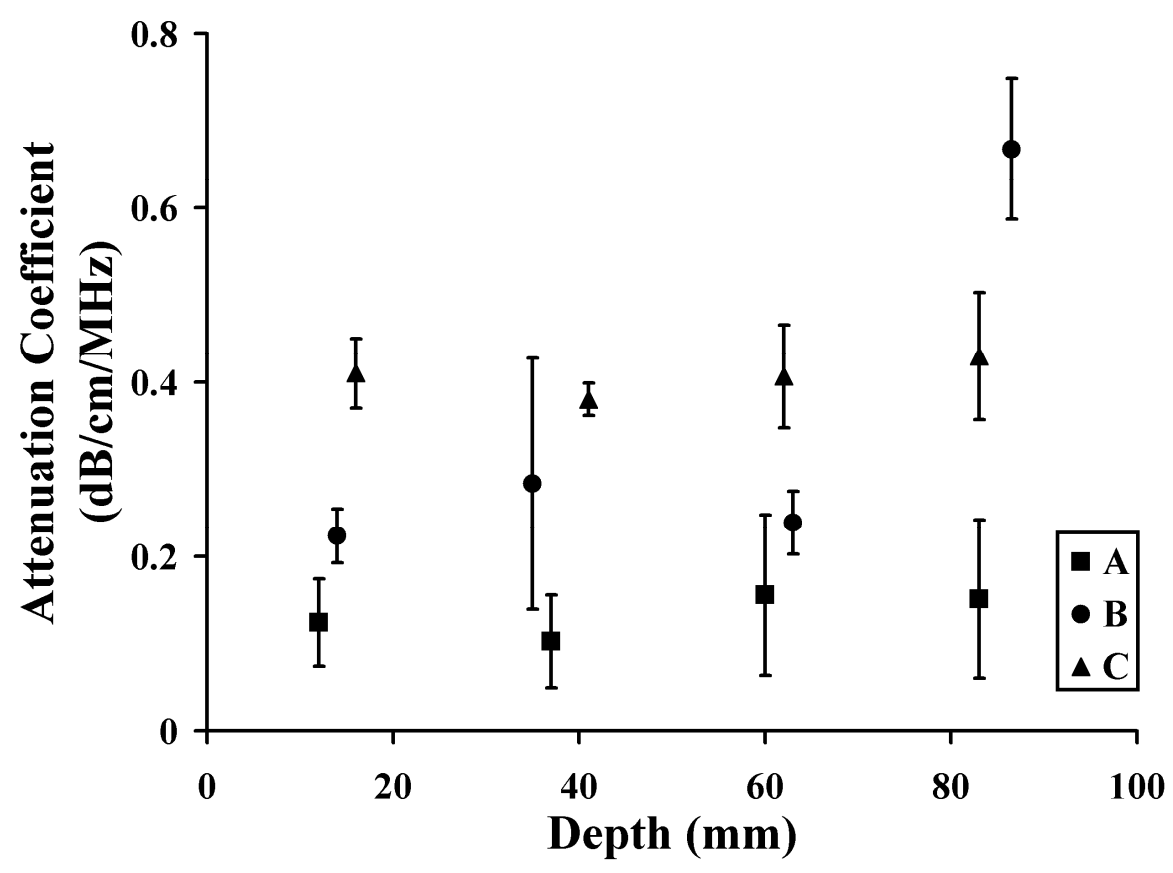

Figure 3. Variation of attenuation coefficient $(\mathrm{dB} / \mathrm{cm} / \mathrm{MHz})$ as a function of depth $(\mathrm{cm})$ in phantoms $\mathrm{A}, \mathrm{B}$ and $\mathrm{C}$ with phantom $\mathrm{A}$ containing no $\mathrm{Al}_{2} \mathrm{O}_{3}$ scatterers, phantom $\mathrm{B}$ containing $0.88 \mathrm{wt} \%$ of $0.3 \mu \mathrm{m} \mathrm{Al}{ }_{2} \mathrm{O}_{3}$ and $0.94 \mathrm{wt} \% 3 \mu \mathrm{m} \mathrm{Al}_{2} \mathrm{O}_{3}$, and phantom $\mathrm{C}$ containing $2 \mathrm{wt} \% 0.3 \mu \mathrm{m}$ $\mathrm{Al}_{2} \mathrm{O}_{3}$, respectively. 
The uniformity of the Young's modulus for the respective phantoms was also investigated to ensure that the addition of the $\mathrm{Al}_{2} \mathrm{O}_{3}$ acoustic scatterers did not affect the homogeneity of the stiffness throughout each phantom. The resultant standard deviation of the stiffness values for each phantom were less than 5\% and thus, as discussed earlier, the scatterers were considered not to affect the Young's modulus homogeneity. The average acoustic velocities for the phantoms were between $1505.3-1506.5 \mathrm{~m} / \mathrm{s}$, a range witnessed in other PVA-cryogel studies (Fromageau et al., 2007; Surry et al., 2004). While the speed of sound measurements are consistent throughout the phantom, the values are lower than the prescribed range of 1560 $1590 \mathrm{~m} / \mathrm{s}$ reported for healthy liver tissue (Lin et al., 1987; Szabo, 2004)

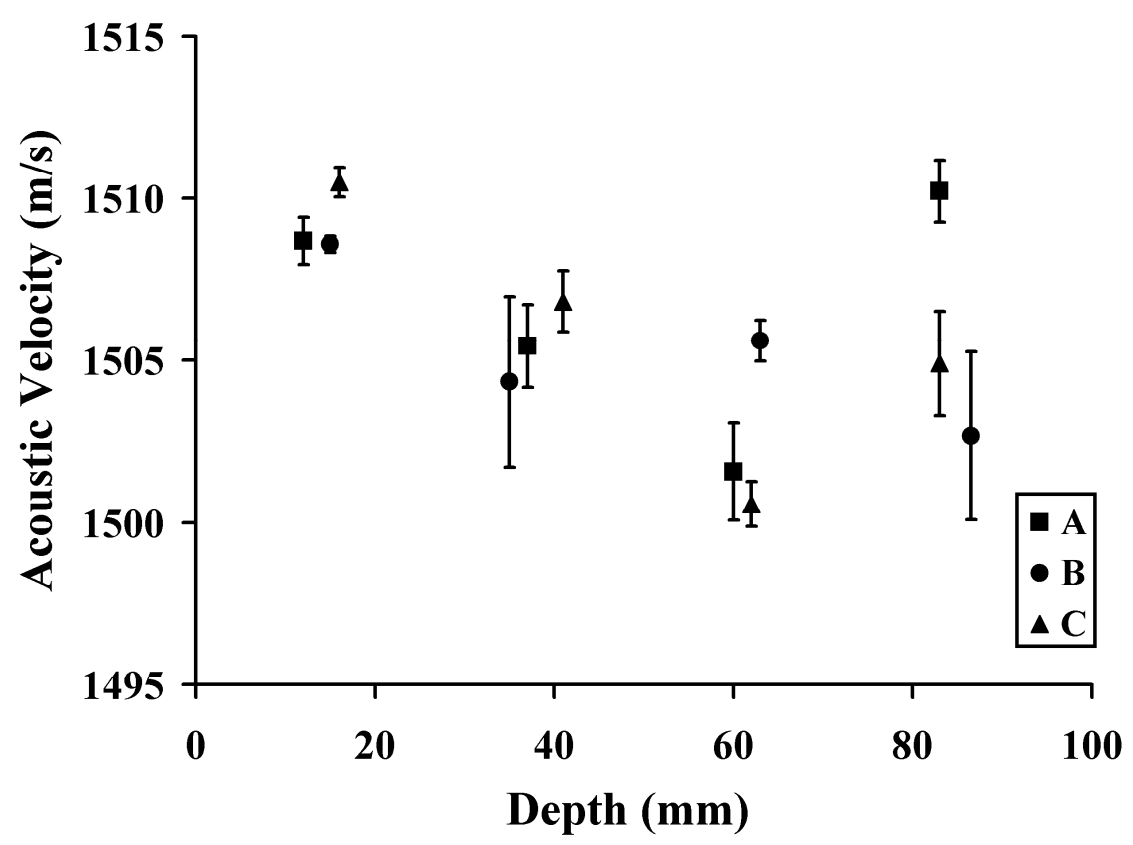

Figure 4. Variation of acoustic velocity $(\mathrm{m} / \mathrm{s})$ as a function of depth $(\mathrm{cm})$ in phantoms $A, B$ and $\mathrm{C}$ with phantom A containing no $\mathrm{Al}_{2} \mathrm{O}_{3}$ scatterers, phantom $\mathrm{B}$ containing $0.88 \mathrm{wt} \%$ of $0.3 \mu \mathrm{m}$ $\mathrm{Al}_{2} \mathrm{O}_{3}$ and $0.94 \mathrm{wt} \% 3 \mu \mathrm{m} \mathrm{Al} \mathrm{O}_{3}$, and phantom $\mathrm{C}$ containing $2 \mathrm{wt} \% 0.3 \mu \mathrm{m} \mathrm{Al}_{2} \mathrm{O}_{3}$, respectively.

\subsection{PVA-cryogel acoustic velocity modification.}

The results of the experiments conducted for investigating the effects of glycerol on the acoustic characteristics are shown in figure 5 where the Young's modulus, acoustic velocity, attenuation coefficient of the samples are plotted as a function of glycerol concentration $(8,12$, and $16 \mathrm{wt} \%)$. A notable increase in the speed of sound was evident with increased glycerol content, with no significant variation in the attenuation coefficient. The acoustic velocity values ranged between $1542-1587 \mathrm{~m} / \mathrm{s}$, demonstrating the versatility of the material in mimicking a wide range of velocities typically found in the body. 
The recommended IEC speed of sound value of $1540 \mathrm{~m} / \mathrm{s}$ for soft tissue was approximately achieved (IEC-1390, 1996), while the acoustic velocity of healthy liver tissue, which has been reported to be in the range $1560-1590 \mathrm{~m} / \mathrm{s}$ also proved attainable (Lin et al., 1987; Szabo, 2004). The attenuation values measured for these phantoms remained constant for increasing glycerol and were found to be within the recommended range of $0.5-0.7 \mathrm{~dB} / \mathrm{cm} / \mathrm{MHz}$ (IEC1390, 1996).
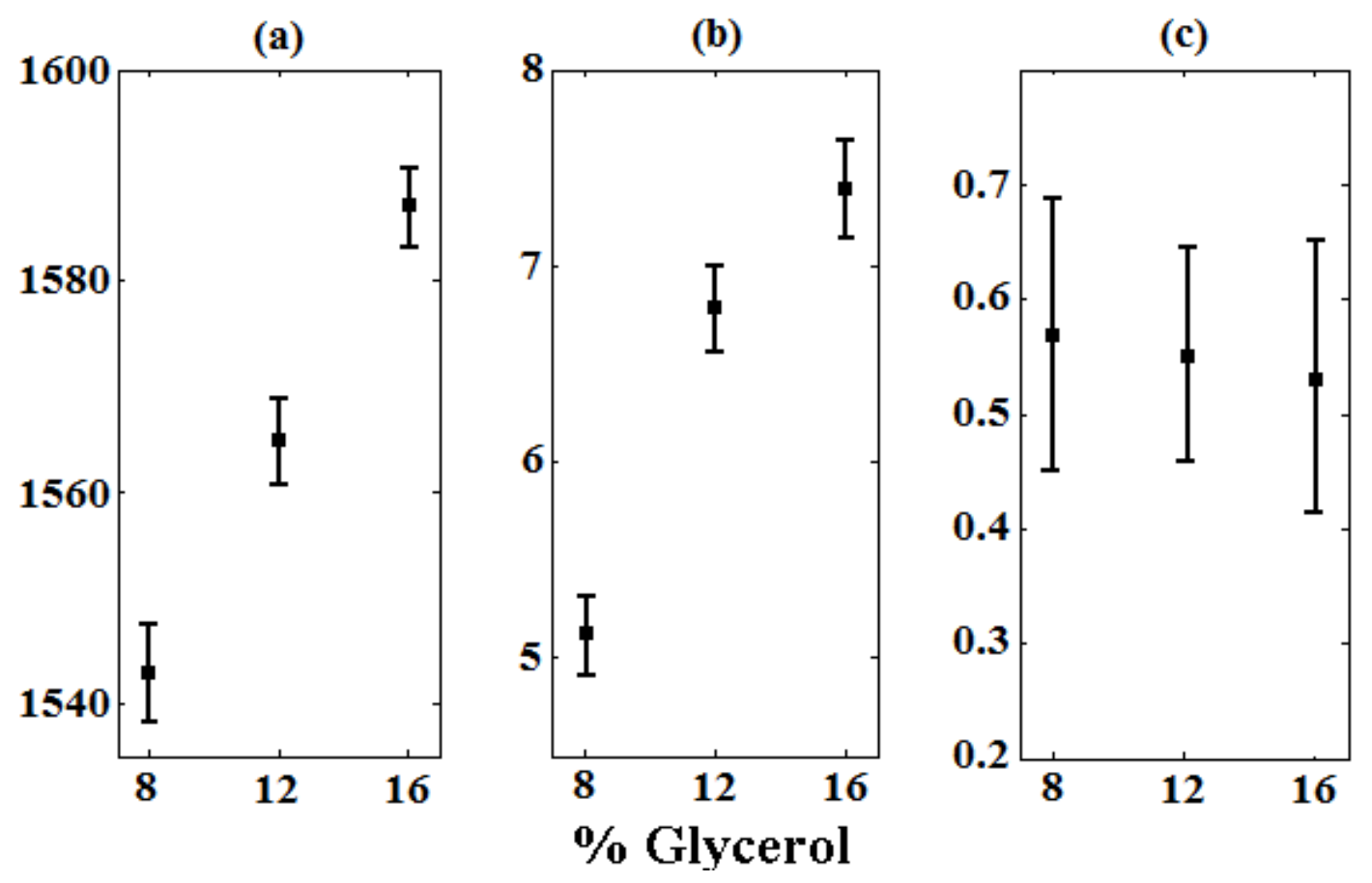

Figure 5. Effect of glycerol concentration on (a) the acoustic velocity $(\mathrm{m} / \mathrm{s})$, (b) Young's modulus values $(\mathrm{kPa})$, and $(\mathrm{c})$ attenuation coefficient $(\mathrm{dB} / \mathrm{cm} / \mathrm{MHz})$ for $6 \%$ PVA-C samples processed through 4 freeze-thaw cycles.

Increasing the glycerol concentration produced a marked increase in stiffness values. In addition to the data presented here, a $20 \%$ by weight glycerol sample was also prepared and processed through the freeze-thaw procedure; however, the resultant material was very brittle and ruptured prior to measurement. Thus, although increasing the glycerol content causes an increase in the achieved stiffness values, it would appear to also affect the gelation process of the PVA-cryogel samples, modifying the robustness of the material. The induced brittleness may be partially due to the thermal conductivity and phase change of the properties of the cryogel material. As discussed in an earlier section, it is necessary for the PVA solution to reach a minimum freezing temperature of $-20^{\circ} \mathrm{C}$ in order for the cross-linking process to be initiated (Fromageau et al., 2007; Surry et al., 2004). With an increased concentration of glycerol, the freezing temperature of the solution is further reduced (Lide, 2004), an effect which may negatively affect cross-linking to the extent where the samples become brittle. Although this feature effectively 
places an upper limit on the achievable acoustic velocity for PVA materials, this should not pose a problem for phantoms designed to study liver scanning systems since appropriate acoustic velocities are already achievable with relatively low glycerol concentrations.

To ensure the addition of glycerol to the phantom blend did not affect the stiffness and speed of sounds uniformity, a cylindrical test phantom of diameter $6.7 \mathrm{~cm}$ and height $10 \mathrm{~cm}$, containing $6 \%$ PVA, $12 \%$ glycerol and $2 \%$ by weight $0.3 \mu \mathrm{m} \mathrm{Al}_{2} \mathrm{O}_{3}$ scatterers was manufactured and sectioned, and its mechanical and acoustic properties tested throughout. The acoustic properties of the phantoms were found to be homogenous, with the acoustic velocity and attenuation coefficient values between $1546-1556 \mathrm{~m} / \mathrm{s}$ and $0.41-0.53 \mathrm{~dB} / \mathrm{cm} / \mathrm{MHz}$ for the sections, respectively. The Young's modulus values varied between $7.4-7.9 \mathrm{kPa}$ with a percentage standard deviation of $3.2 \%$, demonstrating a homogenous Young's modulus throughout.

\subsection{Assessment of the Fibroscan ${ }^{\circledR}$ system}

Details of the 8 PVA-C phantoms produced for assessing the Fibroscan ${ }^{\circledR}$ systems accuracy are shown in table 2 where the percentage by weight poly(vinyl alcohol), number of freeze-thaw cycles, acoustic velocities and mechanically tested Young's elastic modulus values of the phantoms are listed. As discussed in previous sections, PVA-C phantoms were found to be uniform throughout, with measured homogeneities for the acoustic velocity and Young's modulus of less than $1 \%$ and $6 \%$ respectively. Mechanical testing was carried out on sections taken from the top of each phantom, which were assumed to represent the mechanical and acoustic characteristics of the bulk of each phantom. Young's elastic moduli between $1.6-16.1 \mathrm{kPa}$ were measured by compression testing, while the acoustic velocities varied between $1540-1570 \mathrm{~m} / \mathrm{s}$. The Young's modulus of the phantoms increased steadily from 1.6 to $9.6 \mathrm{kPa}$ with increasing PVA concentration and freeze/thaw cycles, with a larger jump in the Young's modulus evident for the final phantom.

The accuracy of the Fibroscan ${ }^{\circledR}$ system was tested as per the phantom examination procedure described earlier, wherein a taut electrostatic discharge (ESD) sheet was placed on top of each phantom to minimize the applied force to the phantoms' surface, in order to avoid probe-induced variations in the stiffness measurements. Such effects have previously been shown to cause a change in shear wave speeds due to an induced anisotropy in the medium (Hughes and Kelly, 1953), which could lead to inaccuracies in stiffness measurements by transient elastography. The Young's modulus values measured by the Fibroscan ${ }^{\circledR}$ system for each phantom were compared with those measured by the 'gold standard' of mechanical testing as shown in figure 6 . 
In all phantoms, the values reported by the Fibroscan ${ }^{\circledR}$ system were consistently higher than those measured by the mechanical testing technique, although in most cases the mechanically tested values were within the half interquartile range errors reported by the Fibroscan ${ }^{\circledR}$ system. While discrepancies between the 'gold standard' technique and transient elastography ranged from 3.2 to $50 \%$, the largest discrepancy was observed in phantom 1 at a stiffness value lower than that seen in the liver. Nevertheless, percentage errors of $20-32 \%$ were observed for phantoms 4, 5 and 7 in a Young's modulus range between 6 to $10 \mathrm{kPa}$, a clinically relevant range representative of the progressive stages of fibrosis. A similar trend has been previously observed, albeit with much larger discrepancies than in this study, where transient elastography measurements were reported to be up to 3 times those acquired by mechanical analysis (Oudry et al., 2009). A similar outcome was also reported in work comparing transient elastography measurements with mechanical tests on PVA-cryogel samples processed through up to 6 freezethaw cycles (Fromageau et al., 2007). In this work, the speed of sound of the constructed phantoms was accounted for in the Young's modulus and Poisson ratio calculations, although discrepancies of up to $48 \%$ were nonetheless measured. In both studies, no complete explanation was given for the discrepancy between the mechanical and transient elastography techniques, although Fromageau et al (2007) alluded to a possible source of error arising from a constant derivation window throughout their study.

Table 2. Young's elastic modulus $(\mathrm{kPa})$ and acoustic velocity $(\mathrm{m} / \mathrm{s})$ of a range of PVA-C phantoms (numbered $1-8$ ) used to assess the accuracy of the Fibroscan ${ }^{\circledR}$ system. The percentage weight (wt \%) and number of freeze-thaw cycles through which each phantom was processed is also detailed.

\begin{tabular}{ccccc}
\hline $\begin{array}{c}\text { Phantom } \\
\text { Number }\end{array}$ & PVA (wt\%) & $\begin{array}{c}\text { No. of } \\
\text { freeze/thaw } \\
\text { cycles }\end{array}$ & $\begin{array}{c}\text { Acoustic velocity } \\
\pm \sigma(\mathrm{m} / \mathrm{s})\end{array}$ & $\begin{array}{c}\text { Young's elastic } \\
\text { modulus } \pm \sigma(\mathrm{kPa})\end{array}$ \\
\hline 1 & 5 & 2 & $1549 \pm 2$ & $1.6 \pm 0.2$ \\
2 & 5 & 3 & $1561 \pm 6$ & $3.2 \pm 0.2$ \\
3 & 5 & 4 & $1540 \pm 4$ & $5.6 \pm 0.3$ \\
4 & 5 & 5 & $1565 \pm 2$ & $6.1 \pm 0.4$ \\
5 & 5 & 6 & $1567 \pm 4$ & $7.0 \pm 0.4$ \\
6 & 6 & 3 & $1560 \pm 3$ & $9.5 \pm 0.6$ \\
7 & 6 & 4 & $1561 \pm 6$ & $9.6 \pm 0.6$ \\
8 & 6 & 5 & $1570 \pm 3$ & $16.1 \pm 1$ \\
\hline
\end{tabular}


Indeed, the speed of sound for which the Fibroscan ${ }^{\circledR}$ system is calibrated will contribute some degree of error to the measured values, particularly when the acoustic velocity of the sample under investigation differs significantly from the calibrated value, which certainly will occur in the clinical setting when one considers that the acoustic velocity of the liver has been observed to vary from $1510 \mathrm{~m} / \mathrm{s}$ to $1590 \mathrm{~m} / \mathrm{s}$ in different fibrosis stages (Meziri et al., 2005). Although the calibrated value of the speed of sound for the Fibroscan ${ }^{\circledR}$ system has not been published by the manufacturers Echosens (Paris), one early report loosely suggests an approximate ultrasonic velocity of $1500 \mathrm{~m} / \mathrm{s}$ (Sandrin et al., 2003), a figure somewhat lower than the reported range of liver tissue discussed above. A difference of acoustic velocity such as this would cause a significant underestimation of the depths of shear wave displacements induced in the healthy liver, and subsequently result in an underestimation of the shear wave velocity. It should be noted that, due to the dependence of the Young's modulus on the square of the shear wave velocity (Equation 6), a relatively small discrepancy between the calibrated and actual sample velocities would affect a correspondingly larger error in the measured Young's moduli. In the current study, the overestimation of the Young's modulus measured by the Fibroscan ${ }^{\circledR}$ suggests that the scanner is possibly calibrated with an acoustic velocity higher than that of the investigated phantoms; however, it is more likely that the overestimation is due to the discrepancies previously observed between values reported by transient elastography and mechanical testing (Oudry et al., 2009; Fromageau et al., 2007).

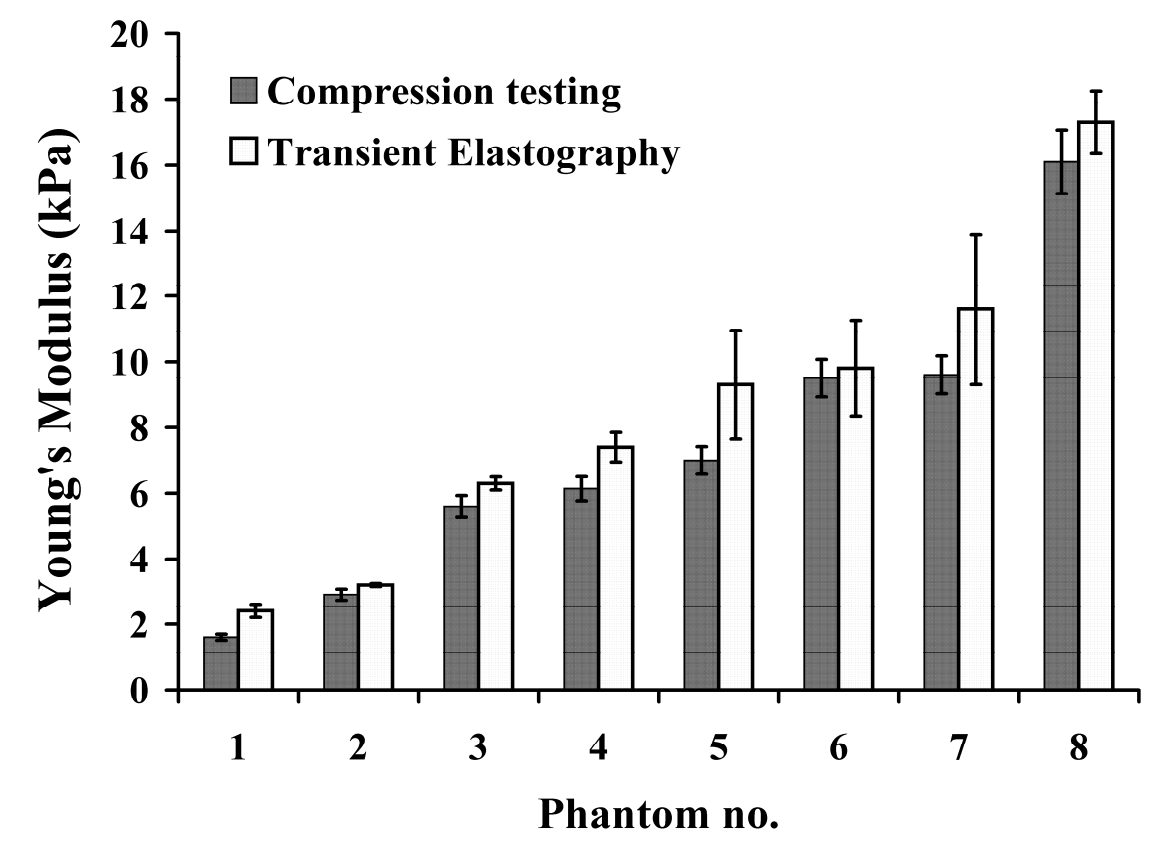

Figure 6. Comparison of the compression-tested Young's elastic modulus $( \pm \sigma)$ and the stiffness values measured by the Fibroscan ${ }^{\circledR}$ system ( \pm Half Inter Quartile Range (IQR/2)). 


\section{Conclusion}

For the first time phantoms of low concentration PVA (5 - 6\%) were processed to achieve a Young's elastic modulus range of between $1.6-16.1 \mathrm{kPa}$, ideal for assessing the accuracy of a liver scanning transient elastography system. A novel technique for achieving the optimum acoustic properties of the cryogel was used by employing glycerol and $0.3 \mu \mathrm{m} \mathrm{Al}_{2} \mathrm{O}_{3}$ scatterers. The versatility of the PVA-C material also suggests the possibility of using PVA across different elastography modalities, possibly in MRE with the addition of paramagnetic dopants to alter the $T_{1}$ and $T_{2}$ relaxation times.

While the cryogel samples were successful in mimicking a range of shear elastic modulus and acoustic velocity values similar to that of the liver, PVA-C is considered to be approximately elastic and therefore does not mimic the shear loss modulus of liver tissue which is considered to be a highly lossy viscoelastic material at a shear wave frequency of $50 \mathrm{~Hz}$ (Asbach et al., 2008). For the purpose of this study, however, the properties of PVA-C were considered ideal for assessing the accuracy of the Fibroscan ${ }^{\circledR}$ system.

Constructing and processing the samples sometimes proved difficult, with a large increase observed in the stiffness values on going from 5 to 6 freeze/thaw cycles in phantoms 7 and 8 . Similarly, the acoustic velocity values of phantoms 1 and 3 were slightly lower than the other phantoms, although only marginally, even though $13 \%$ by weight glycerol was used for each. In previous studies, it has been suggested that larger phantoms provide a more accurate assessment of transient elastography systems; however, given the influence of the thawing rate on the stiffness of the cryogel material, the size of phantoms were limited so as to ensure a relatively uniform thawing rate throughout, thus producing a uniform stiffness. Furthermore, while the depth profiles in the phantom sectioning experiments displayed relatively homogenous stiffness and acoustic values throughout sections of the phantoms, investigations as to the homogeneity within sections used for compression measurements were not carried out. Accordingly, although the cryogel phantoms exhibited a wide range of acoustic and mechanical tissue mimicking characteristics proving ideal for elastography system assessment, there are limitations associated with the material.

Overall, the measurements performed by the Fibroscan ${ }^{\circledR}$ system were close to the mechanically tested measurements. The difference could have been caused by the set-up of the phantom and inherent changes in the cryogel with the application of the probe, or also due to a mismatch in the speed of sounds of the cryogel and that for which the scanner is calibrated. Nevertheless, it should be noted that the compression tested values for most phantoms fell within the measured half interquartile ranges reported by the Fibroscan ${ }^{\circledR}$ system. In some cases the IQR was quite 
broad, reflecting a large spread in the 10 measurements recorded by the scanner for each exam. It should be highlighted that if there is a mismatch between the speed of sound assumed by the scanner and that of the interrogated medium, a less accurate stiffness value may result. Thus, unless the acoustic velocity for which the scanner is calibrated is perfectly matched to that of the interrogated volume, the Young's modulus value returned by the Fibroscan ${ }^{\circledR}$ system will not accurately measure the stiffness of the liver tissue, reflecting the inherent limitation of the single-point acoustic velocity calibration of such systems. Furthermore, while the Fibroscan ${ }^{\circledR}$ system assumes that liver tissue is approximately elastic for the purposes of estimating stiffness values, in reality the liver is a highly lossy viscoelastic medium (Asbach et al., 2008) and thus the assumption that shear wave velocity is directly related to the stiffness may not be strictly correct and warrants further investigation. With the possible development of new elastography scanners also capable of measuring liver stiffness values, discrepancies in reported Young's modulus data may become evident between newer scanners and the Fibroscan ${ }^{\circledR}$ system due to differences in methods of data acquisition and speed of sound calibration.

Research detailing the acoustic velocities of different stages of liver fibrosis have reported a range of between $1510-1590 \mathrm{~m} / \mathrm{s}$ (Meziri et al., 2005), highlighting the possible variations in the tissue. In addition, an increase in the fat content of the liver has previously been shown to cause a reduction in the speed of sound (Hill et al., 2004; Lin et al., 1987). Therefore, different fat content in livers of equal Young's moduli would result in different stiffness measurements reported by transient elastography techniques. Studies using the Fibroscan ${ }^{\circledR}$ system to determine cut-off stiffness values for diagnosing cirrhosis have reported varying thresholds depending on the cause of liver cirrhosis (Castéra et al., 2005; Nguyen-Khac E, 2007; GanneCarrié et al., 2006). Cut-off values of $12.5 \mathrm{kPa}$ have been reported for the diagnosis of viral hepatitis C cirrhosis (Castéra et al., 2005), while alcoholic liver disease and non-alcoholic fatty liver disease have been reported to show significantly higher cut-offs of $19-21.5 \mathrm{kPa}$ (NguyenKhac E, 2007; Ganne-Carrié et al., 2006) and $17.5 \mathrm{kPa}$ (Yoneda et al., 2008), respectively. Accordingly, in addition to the differing distribution of hepatic fibrosis influencing the cut-offs for different liver conditions (Nguyen-Khac et al., 2008), a variation in the fat content of the liver, and thus the acoustic velocity, may also influence the cut-off values established by the Fibroscan ${ }^{\circledR}$ system. Thus, the stiffness values reported by the Fibroscan ${ }^{\circledR}$ system may not fully describe the absolute Young's modulus of the liver, but more represent a figure which is useful when compared to other examination data for the same disease. As has been suggested in the literature, when using the Fibroscan ${ }^{\circledR}$ system as a diagnosis tool, knowledge of the cirrhosisinducing cause is necessary when choosing a stiffness cut-off value (Nguyen-Khac et al., 2008). In addition, it has also been recommended that the scan be used in combination with another non-invasive method to improve the accuracy of the liver fibrosis staging (Castera et al., 2008; 
Yoshioka et al., 2008). Hence, although the Fibroscan ${ }^{\circledR}$ is proving to be a useful tool for monitoring stiffness of the liver, biopsy should remain the gold standard until such a time as fibrosis staging can be more accurately identified by the scanner.

\section{Acknowledgements}

We gratefully acknowledge Neil Branigan and John McNamara of the Manufacturing Engineering Dept., Dublin Institute of Technology (DIT) for assistance with the mechanical testing, and Deirdre King of the Medical Ultrasound Physics and Technology Group, DIT for assistance with the TMM preparation.

\section{References}

Asbach P, Klatt D, Hamhaber U, Braun J, Somasundaram R, Hamm B and Sack I 2008 Assessment of liver viscoelasticity using multifrequency MR elastography. Magn Reson Med 60 373-9

Bedossa P and Poynard T 1996 An algorithm for the grading of activity in chronic hepatitis C. The METAVIR Cooperative Study Group. Hepatology 24 289-93

Browne J, Ramnarine K, Watson A and Hoskins P 2003 Assessment of the acoustic properties of common tissue-mimicking test phantoms. Ultrasound Med Biol 29 1053-60

Brusseau E, Fromageau J, Finet G, Delachartre P and Vray D 2001 Axial strain imaging of intravascular data: results on polyvinyl alcohol cryogel phantoms and carotid artery. Ultrasound Med Biol 27 $1631-42$

Castera L, Forns X and Alberti A 2008 Non-invasive evaluation of liver fibrosis using transient elastography. J Hepatol 48 835-47

Castéra L, Vergniol J, Foucher J, Le Bail B, Chanteloup E, Haaser M, Darriet M, Couzigou P and De Lédinghen V 2005 Prospective comparison of transient elastography, Fibrotest, APRI, and liver biopsy for the assessment of fibrosis in chronic hepatitis C. Gastroenterology 128 343-50

Chu K and Rutt B 1997 Polyvinyl alcohol cryogel: an ideal phantom material for MR studies of arterial flow and elasticity. Magn Reson Med 37 314-9

CIRS 2009 Elasticity QA Phantom Model 049 specifications. CIRS Tissue Simulation \& Phantom Technology)

Culjat M, Goldenberg D, Tewari P and Singh R 2010 A review of tissue substitutes for ultrasound imaging. Ultrasound Med Biol 36 861-73

Céspedes I, Ophir J, Ponnekanti H and Maklad N 1993 Elastography: elasticity imaging using ultrasound with application to muscle and breast in vivo. Ultrason Imaging 15 73-88

de Korte C, Ignacio Céspedes E, van der Steen A and Lancée C 1997 Intravascular elasticity imaging using ultrasound: feasibility studies in phantoms. Ultrasound Med Biol 23 735-46

de Lédinghen V and Vergniol J 2008 Transient elastography (FibroScan). Gastroenterol Clin Biol 32 5867

Deprez J, Cloutier G, Schmitt C, Gehin C, Dittmar A, Basset O and Brusseau E 2007 3D ultrasound elastography for early detection of lesions. evaluation on a pressure ulcer mimicking phantom. Conf Proc IEEE Eng Med Biol Soc 2007 79-82

Fromageau J, Brusseau E, Vray D, Gimenez G and Delachartre P 2003 Characterization of PVA cryogel for intravascular ultrasound elasticity imaging. IEEE Trans Ultrason Ferroelectr Freq Control 50 1318-24

Fromageau J, Gennisson J, Schmitt C, Maurice R, Mongrain R and Cloutier G 2007 Estimation of polyvinyl alcohol cryogel mechanical properties with four ultrasound elastography methods and comparison with gold standard testings. IEEE Trans Ultrason Ferroelectr Freq Control 54 498509

Fung Y-c 1993 Biomechanics: Mechanical Properties of Living Tissues: Springer)

Ganne-Carrié N, Ziol M, de Ledinghen V, Douvin C, Marcellin P, Castera L, Dhumeaux D, Trinchet J and Beaugrand M 2006 Accuracy of liver stiffness measurement for the diagnosis of cirrhosis in patients with chronic liver diseases. Hepatology 44 1511-7

Gao L, Parker K, Lerner R and Levinson S 1996 Imaging of the elastic properties of tissue--a review. Ultrasound Med Biol 22 959-77 
Hassan C, Stewart J and Peppas N 2000 Diffusional characteristics of freeze/thawed poly(vinyl alcohol) hydrogels: applications to protein controlled release from multilaminate devices. Eur J Pharm Biopharm 49 161-5

Hill C R, Bamber J C and ter Haar G R 2004 Physical Principles of Medical Ultrasonics: Wiley)

Hughes D S and Kelly J L 1953 Second-order elastic deformation of solids. Phys Rev 921145

IEC-1390 1996 Real-time pulse-echo systems-Guide for test procedures to determine performance specifications International Electrotechnical Commission 1390

ISO-7743 2008 Rubber, vulcanized or thermoplastic - Determination of compression stress-strain properties. (Sweden

King D M 2009 Development of Renal Phantoms for the Evaluation of Current and Emerging Ultrasound Technology. (Dublin: Dublin Institute of Technology)

Klinkosz T, Lewa C and Paczkowski J 2008 Propagation velocity and attenuation of a shear wave pulse measured by ultrasound detection in agarose and polyacrylamide gels. Ultrasound Med Biol 34 265-75

Lide D R 2004 CRC Handbook Chemistry and Physics

Lin T, Ophir J and Potter G 1987 Correlations of sound speed with tissue constituents in normal and diffuse liver disease. Ultrason Imaging 9 29-40

Luo J and Konofagou E 2009 Effects of various parameters on lateral displacement estimation in ultrasound elastography. Ultrasound Med Biol 35 1352-66

Madsen E, Hobson M, Shi H, Varghese T and Frank G 2005 Tissue-mimicking agar/gelatin materials for use in heterogeneous elastography phantoms. Phys Med Biol 50 5597-618

Madsen E, Hobson M, Shi H, Varghese T and Frank G 2006 Stability of heterogeneous elastography phantoms made from oil dispersions in aqueous gels. Ultrasound Med Biol 32 261-70

McGill D, Rakela J, Zinsmeister A and Ott B 1990 A 21-year experience with major hemorrhage after percutaneous liver biopsy. Gastroenterology 99 1396-400

Meziri M, Pereira W, Abdelwahab A, Degott C and Laugier P 2005 In vitro chronic hepatic disease characterization with a multiparametric ultrasonic approach. Ultrasonics 43 305-13

Nahon P, Kettaneh A, Tengher-Barna I, Ziol M, de Lédinghen V, Douvin C, Marcellin P, Ganne-Carrié N, Trinchet J and Beaugrand M 2008 Assessment of liver fibrosis using transient elastography in patients with alcoholic liver disease. J Hepatol 49 1062-8

Nava A, Mazza E, Furrer M, Villiger P and Reinhart W 2008 In vivo mechanical characterization of human liver. Med Image Anal 12 203-16

Nguyen-Khac E and Capron D 2006 Noninvasive diagnosis of liver fibrosis by ultrasonic transient elastography (Fibroscan). Eur J Gastroenterol Hepatol 18 1321-5

Nguyen-Khac E, Capron D, Braillon A and Dupas J L 2008 The non-invasive diagnosis of cirrhosis using the Fibroscan must be performed with cause-specific stiffness cut-offs Gut online 571630

Nguyen-Khac E R B, Brevet M, et al. 2007 Assessment of asymptomatic liver fibrosis in alcohol abuser patients by transient elastography (Fibroscan). J. Hepatol 46(Suppl 1) S280.

Onda 2006 Acoustic velocity of Liquids. Onda Corporation Ltd.)

Oudry J, Bastard C, Miette V, Willinger R and Sandrin L 2009 Copolymer-in-oil phantom materials for elastography. Ultrasound Med Biol 35 1185-97

Park E and Maniatty A 2006 Shear modulus reconstruction in dynamic elastography: time harmonic case. Phys Med Biol 51 3697-721

Pazos V, Mongrain R and Tardif J 2009 Polyvinyl alcohol cryogel: optimizing the parameters of cryogenic treatment using hyperelastic models. J Mech Behav Biomed Mater 2 542-9

Ramnarine K, Nassiri D, Hoskins P and Lubbers J 1998 Validation of a new blood-mimicking fluid for use in Doppler flow test objects. Ultrasound Med Biol 24 451-9

Rojkind M G P 2001 The Liver: Biology and Pathobiology, ed B J Arias IM, Chisari FV, Fausto N, Schachter D, (Philadelphia: Lippincot Williams \& Wilson) pp 721-38

Royer D and Dieulesaint E 2000 Elastic Waves in Solids vol 1: Springer)

Sandrin L, Fourquet B, Hasquenoph J, Yon S, Fournier C, Mal F, Christidis C, Ziol M, Poulet B, Kazemi F, Beaugrand M and Palau R 2003 Transient elastography: a new noninvasive method for assessment of hepatic fibrosis. Ultrasound Med Biol 29 1705-13

Sandrin L, Tanter M, Gennisson J, Catheline S and Fink M 2002 Shear elasticity probe for soft tissues with 1-D transient elastography. IEEE Trans Ultrason Ferroelectr Freq Control 49 436-46

Schwan H P and Carstensen E L 1952 Ultrasonics aids diathermy experiments Electronics 216.

Surry K, Austin H, Fenster A and Peters T 2004 Poly(vinyl alcohol) cryogel phantoms for use in ultrasound and MR imaging. Phys Med Biol 49 5529-46

Szabo T 2004 Diagnostic Ultrasound Imaging_Inside out.: Boston, MA: Elsevier)

Verveer C and de Knegt R 2006 Non-invasive measurement of liver fibrosis: application of the FibroScan in hepatology. Scand J Gastroenterol Suppl 85-8 
WHO 2000 WHO Fact sheet

Yamakoshi Y, Sato J and Sato T 1990 Ultrasonic imaging of internal vibration of soft tissue under forced vibration. IEEE Trans Ultrason Ferroelectr Freq Control 37 45-53

Yeh W, Li P, Jeng Y, Hsu H, Kuo P, Li M, Yang P and Lee P 2002 Elastic modulus measurements of human liver and correlation with pathology. Ultrasound Med Biol 28 467-74

Yoneda M, Mawatari H, Fujita K, Endo H, Iida H, Nozaki Y, Yonemitsu K, Higurashi T, Takahashi H, Kobayashi N, Kirikoshi H, Abe Y, Inamori M, Kubota K, Saito S, Tamano M, Hiraishi H, Maeyama S, Yamaguchi N, Togo S and Nakajima A 2008 Noninvasive assessment of liver fibrosis by measurement of stiffness in patients with nonalcoholic fatty liver disease (NAFLD). Dig Liver Dis $\mathbf{4 0} 371-8$

Yoshioka K, Kawabe N and Hashimoto S 2008 Transient elastography: Applications and limitations. Hepatol Res 38 1063-8

Zhou K and Lu L 2009 Assessment of fibrosis in chronic liver diseases. J Dig Dis 10 7-14

Ziol M, Handra-Luca A, Kettaneh A, Christidis C, Mal F, Kazemi F, de Lédinghen V, Marcellin P, Dhumeaux D, Trinchet J and Beaugrand M 2005 Noninvasive assessment of liver fibrosis by measurement of stiffness in patients with chronic hepatitis C. Hepatology 41 48-54 